C2006 IEEE. Personal use of this material is permitted. However, permission to reprint/republish this material for advertising or promotional purposes or for creating new collective works for resale or redistribution to servers or lists, or to reuse any copyrighted component of this work in other works must be obtained from the IEEE. 


\title{
Trust Issues in Service Oriented Environment
}

\author{
Farookh Khadeer Hussain, Elizabeth Chang, Member, IEEE and Tharam S. Dillon, Fellow, IEEE
}

\begin{abstract}
Service Oriented Environment (SOE) is new paradigm for carrying out business activities on the internet. In this paper I give an introduction to the concept of service oriented environment and discuss the different activities carried out in the SOE and different entities involved in SOE. The issues related to trust in service oriented environment and proposed and explained.
\end{abstract}

Index Terms-Service Oriented Environment, Service Oriented Architecture, Trust, Agent, Product, and Service.

\section{SERVICE ORIENTED ENVIRONMENT}

The advent of the Web and its intrusion into business, commerce, government and the health sector have led to Web based e-commerce for business interactions and collaborations over great distances and at any time. In the last ten years, this new Web based environment has enabled economic growth, industry development, technology innovation, and resource sharing. This new business environment has led to the development of the Service-Oriented Environment (SOE), that transcends the previous static, closed, competitive models and has moved towards flexible, open, collaborative, sharing and distributed environments that are able to respond in a timely manner to consumer needs and business dynamics inherent in the networked economy.

We define Service-Oriented Environment as a collaborative, shared and open community in which agents utilize its infrastructure and technology to carry out business activities, such as product sales, service deliveries and information retrieval. Service Oriented Environment has at least four components: Agents, Business Activities, Infrastructure, and Technology. In the section I propose the different components of service oriented environment.

Farookh Khadeer Hussain is with the Centre of Extended Enterprises, School of Information System, Curtin Business School, Perth, WA, Australia. (His contact details are as follows: phone: 0061-08-92662875; fax: 0061-0892662861; e-mail: Farookh.Hussain@cbs.curtin.edu.au).

Professor Elizabeth Chang is the director of the Centre of Extended Enterprises, School of Information System, Curtin Business School, Perth, WA, Australia. (Her contact details are as follows: phone: 0061-08-92662875; fax: 0061-08-92662861; e-mail: Elizabeth.Chang@cbs.curtin.edu.au).

Professor Tharam S. Dillon is the dean of the Faculty of Information Technology, University of Technology, Sydney. Sydney, NSW, Australia. (His contact details are as follows: phone: 0061-02-95141800; e-mail: tharam@it.uts.edu.au).

1-4244-03 18-9/06/\$20.00 (C)2006 IEEE

\section{COMPONENTS OF SERVICE ORIENTED ENVIRONMENT}

\section{A. Agents (Buyers, Sellers/Providers, Users, Websites or} Servers)

An agent in business terms are often referred to as intelligent representatives, acting on behalf of a company, business or an individual and having the power, authority and ability to make decisions or carry out business activities. It can be a buyer, seller, supplier, merchant, website, service consumer, service provider or an interacting peer, a software construct, or an intelligent server running behind the scenes on the network.

\section{B. Business Activities}

In a Service-Oriented environment, business activities includes all the management processes and workflows enabling a company or service provider to sell or deliver its products and services (through the use of technologies and infrastructure) to the service consumer or end user. In a service oriented environment a business activity could be any of the following

- Product Sales: In a Service-Oriented environment are goods or finished products that are sold to or for sale to consumers. The Quality of a Product ( $Q O P$ ) can be evaluated or rated by consumers who use the product or customers who bought the product. Quality of Product $(Q O P)$, in a Service-Oriented network environment, is defined as the fulfilment of mutually agreed functionality of the product. In Service Oriented Environment, a product could refer to pure information such as weather information or drug information which is provided by an information provider. Information retrieved from Service-Oriented networks are also products, regardless of whether they are free or not, because results, reports, documents or information are produced and may be the product of research or development, or an information providers product. They may sell the information as a form of product. For example, IEEE has one of the world's largest scientific article collections, and they sell scientific papers as products

- Service: In a Service-Oriented Environment the term 'service' refers to jobs, duties, tasks or activities that a business or a service provider offers to customers or consumers that have some economic value. In this thesis we make use of the term service to refer to any 
activity that has an associated financial value provided by a given service provider to a service requestor. An example of service trust is logistics services (they have trucks or trains that can deliver goods or products for you) for a given amount of money. Quality of Service $(Q O S)$, in a Service-Oriented network environment, is defined as the fulfilment of the service agreement or mutually agreed service (agreed between the service provider and the service consumer) by the service provider.

- Collaborating with another agent to achieve a desired result: An agent in service oriented environment could choose to interact or collaborate with another agent in order to achieve a desired outcome. An example of such collaboration between agents is Heatware (www.heatware.com) in which an agent interacts or carries out a virtual transaction with another agent, in order to achieve its desired result or goal. In these portals the agent initiating the interaction or the agent who wants to achieve desired results collaborates with another agent who is capable of fulfilling the desired objectives. In contrast to service, which as mentioned before has financial aspects involved, the activities performed by collaborating agents in order to achieve a desired outcome have no financial or economic value.

An example of such agent-to-agent collaboration which has no financial aspects is the Peer-to-Peer Model for Interacting Agents in Peer-to-Peer Networks like Gnutella, Kazaa.... etc. These peer-topeer networks are a very popular platform for file sharing. File sharing is the practice of making files available for other users to download over the Internet and smaller networks. Usually file sharing follows the Peer-to-Peer (P2P) model, where the files are stored on and served by personal computers of the users. Most people who engage in file sharing are also downloading files that other users share. As can be seen, the peers or agents are interacting with each other to achieve a common desired goal (in this case to download files).However the interaction between them involves no financial or economic value. A

File Sharing Networks are just one example of Peer-to-Peer Collaborations which do not involve any financial value. Social Interactions or Cultural Interactions between two communicating agents is another example of collaborations which do not involve any financial value. In such a scenario, the agent imitating the interaction would assign trustworthiness to its other interacting partner.

\section{Infrastructures (Networks communications)}

In Service-Oriented environments the infrastructure mainly refers to the Internet and communication mechanism for carrying out the business related activities. In the early days of e-commerce, business and transactions were mostly carried out over client-server environments. Since then, many other forms of network infrastructure have come into use. Even though not all the infrastructures are totally mature, they are regarded as the next generation of e-Commerce or e-Business platforms. The network infrastructures that can be used in Service-oriented environments are:

- Client-server network

- Peer-to-peer network

- Grid service network

- Ad-hoc network

- Mobile network

Any one of these network infrastructures, when provided within a Service-oriented environment, permit e-Business (total e-solution), e-Commerce (online transactions) and eservice to be carried out.

\section{Technologies (service publishing, discovery, binding and composition)}

A typical service oriented architecture (SOA) consists of the interactions between three roles, as shown in Figure 1.9, namely Service Providers, Service Requesters and Service Brokers. They also involve three distinct activities namely 1) Description and Publishing, 2) Finding and Discovery and 3) Binding. I explain these terms in more detail below.

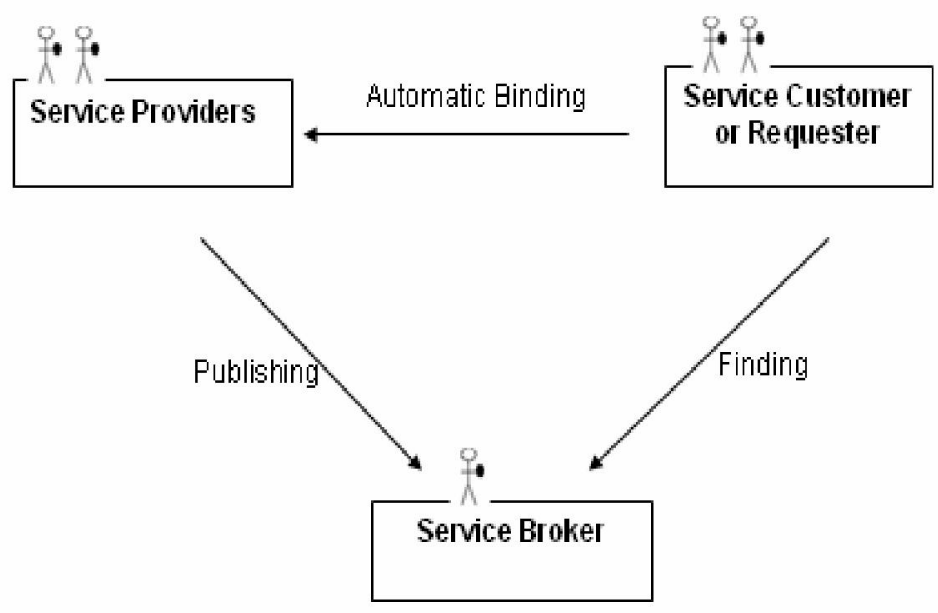

\section{Figure 1 Service-Oriented Architecture}

Service Provider: The major task of the service provider is to have their services deliverable, described and published. Such publishing could be by registering with the service broker or making them available to service requesters directly (Roy \& Ramanujan, 2001)

Service Requester: Service customers or requesters may be either machines or humans. The service requesters find or discover the desired services from the service brokers or directly from service providers. Then they request those services, by sending messages, to either Service brokers or the Service Providers directly. Once the service provider has been located, the service customers or requesters then bind to those services directly with the service provider. 
Service Broker: Service brokers provide central repositories or directories for services published by Service providers. Basically, there are two types of service brokers; public brokers and private brokers. Public brokers are publicly available through the Internet or for open community, while private brokers are limited in access for only authorized groups or a closed community. A service broker has to be centralized in this regard, but service binding is distributed.

As mentioned above, Description and Publishing, Finding and Discovery and Binding are the underlying principles of the Service-oriented architecture framework.

Description and Publishing: Service providers have to provide a precise description of the services and the mechanisms by which are accessed and publish their services with the Broker or Central registry.

Finding and Discovery: A Service requester or customer looking for a particular service does so by putting out request for the service providing a precise description of the service. This could be responded to by the Broker or Central Registry or alternatively by the service provider directly.

Binding: Calling or invoking a service such as GetLastUKTradePrice. This invocation will be transmitted over the network and bring the answer or deliver of the service to the customer or service requester.

An environment or setting which employs the service oriented architecture as a means for carrying out its activities is termed as the Service Oriented Environment. The Service Oriented Environment is a collaborative environment because it is not a closed walled individual operation as carried out in a traditional business sense. Online users are often anonymous but help can be provided for each of them by posting and answering questions on the Web, and carrying out collaborative business, research or industrial processes. New users can join this environment at will and can exit the environment at all. There are no constraints or regulations on who can participate and who cannot participate in such a collaborative environment.

It is a shared environment because agents share information on the Web about unknown agents, unknown products, unknown service providers, or merchants.

It is an open community environment because agents attach themselves to or leave the community as they need to rather than having a predefined set of agents listed within the community functions. Also, everything is on the Web, coupled with emerging trusted technologies that ascertain the behaviour of sellers, producers, merchants, manufacturers including service providers using ratings by all kinds of online users, or other buyers, sellers, etc.

The following diagram depicts the Service-oriented environment and its major entities.

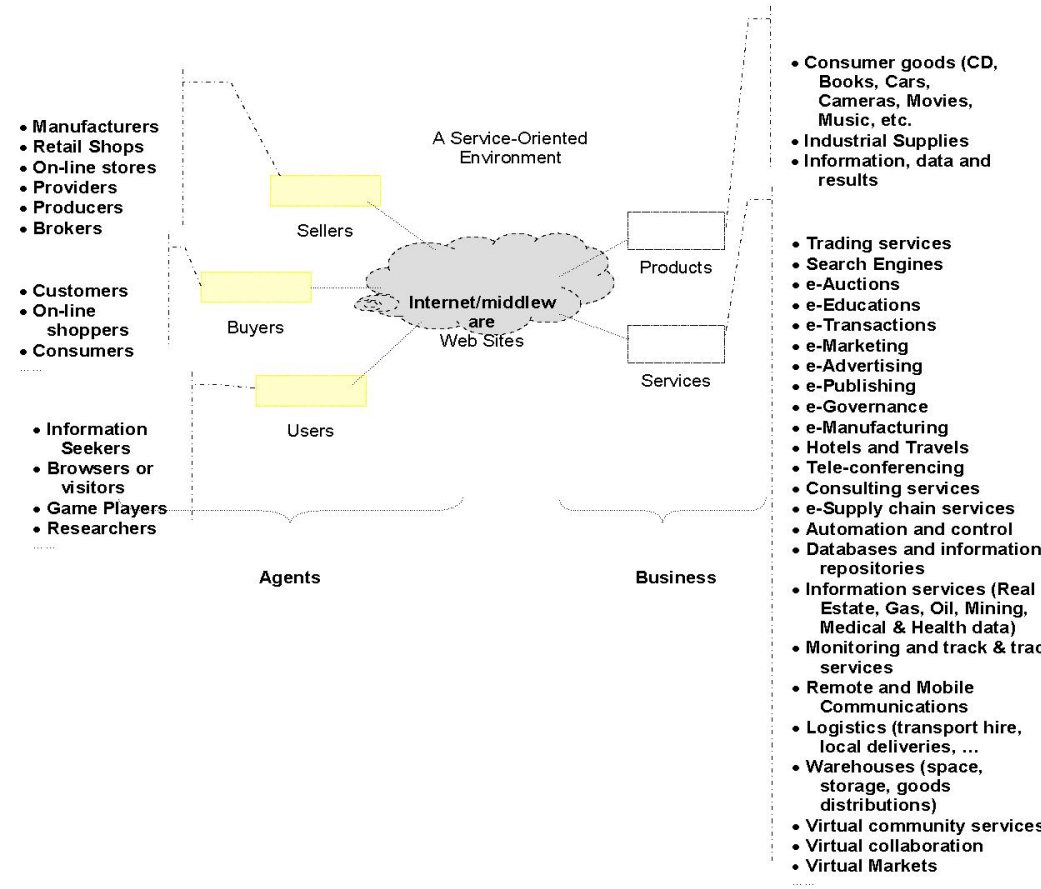

\section{Figure 2 Major entities in Service-Oriented Environments}

The Service-Oriented Environment has the following characteristics:

1. Multiple channels of sales, marketing, purchasing and information inquiries;

2. A collaborative approach between sellers, buyers, users and service providers;

3. High connectivity and electronic handling of information, data and documents;

4. Strong information infrastructure that extends beyond the original physical individuals and businesses;

5. Provision of products, services, end user interaction and utilization of information services;

6. Self-organization and reconfiguration to meet dynamic business needs;

7. Capturing business intelligence through trust, reputation and smart information sharing; and

8. Value added consumer relationships, customer service and strengthened small-medium businesses.

The Service-oriented environment redefines the old industrial business models by means of new Internet based technologies in order to maximize productivity, customer value and quality of service. In the next section, we list the issues related to trust in service oriented environment.

\section{ISSUES IN SERVICE-ORIENTED ENVIRONMENT}

Trust plays a crucial role in Service-oriented environments which is totally distributed, remote, and heterogeneous. It 
involves several issues that need to be understood and addressed, such as the fact that:

- It is hard to assess the trustworthiness of remote unknown entities over the Internet; this includes the quality of a product and the quality of a service or the trustworthiness of a collaborating agent.

- How can a service consumer or end user gather information about an unknown service provider or an unknown product and make a decision of whether or not to interact with the service provider or the product;

- It is hard to distinguish between the

- high quality of service and low quality of service and

- $\quad$ high quality of product and low quality of product

- $\quad$ high trustworthiness value of agent and low trustworthiness value of agent

on the Internet;

- It is possible to allow people to assess a much wider range of cues related to trustworthiness in the physical world than is currently possible through the Internet;

- Short-cut communication for which the information provided is not comprehensive and sometimes incomplete, e.g., insufficient information about the service providers, goods or products as well as published services; and online users and consumers often have to take 'risks' which can leave them in a vulnerable position;

- An attractive website offers little evidence about the solidity of the organization behind it;

- Customers may be misled by the attractiveness of a given website and may find attractiveness of a website as being directly proportional to the solidity of the organization behind it;

- The online user or consumer has no opportunity to see and try the products, or 'squeeze the tomatoes before you buy';

- The provider or seller, on the other hand, may not know whether he or she will get paid properly or ontime by the customers or consumers;

- Existing trustworthiness systems have their own way of carrying out data entry or enquiry and can have different representations, interaction styles and trust rating scales. Some use 5 stars, some use 4 stars, some use a scale of 1-10, some use percentages, and some use unbounded integers;

- The existing trustworthiness systems are not compatible with each other. In other words the trust rating of a user in a given trustworthiness system cannot be carried over to another trustworthiness systems.

- The fewer the number of people participating in a trustworthiness rating system, the more inadequate the opinions or recommendations provided by the system;

- The effectiveness of any Recommender System is dependent on many factors not just the quality of the algorithm [1];
Unlike the traditional e-Commerce platform, the new set of trustworthiness technologies and systems for Service-oriented environments is reshaping business intelligence through building trust relationships with end users and consumers, learning from customers and competitors and improving customer service and business performance through creating trust, reputation and consumer confidence. The new set of technologies provides a platform for sellers, service providers, websites, manufacturers, business partner's customers, buyers and end users to learn from each other about their trustworthiness and reputation.

From a service provider's point of view, such an automated system would assist business in finding out what customers/consumers really want, what they like and dislike, and take customers'/consumers' input as an opportunity to improve their relationships with them.

From a consumer's point of view, such an automated system provides for online sensations such as being able to 'squeeze the tomatoes before you buy' or enables them to seek other opinions before they undertake a deal or make a transaction.

The adoption of such technology and systems becomes more and more important in today's e-business, as many large sites have started utilizing a portion of the technology already. It is such an important technology that every online business and service provider will have to take advantage of it to maintain their competitiveness. This is because it may provide the necessary technology to improve customer service, to boost consumer confidence and to help with a business's reputation. It may also enhance consumer learning and facilitate them being able to seek the best value online.

\section{CONCLUSION AND FUTURE WORK}

In this paper I gave a brief introduction to the notion of service oriented environment. I then explained all the entities and the business activities carried out in the environment. I then examined the set of issues related to trust in the service oriented environment that have not been addressed. In out future work, I intend to addresses these issues. Further information related to service oriented environment and the trust issues specific to service oriented environment can be found in [1].

\section{REFERENCES}

[1] Elizabeth Chang, Tharam Dillon and Farookh Khadeer Hussain, Trust and Reputation in Service Oriented Environments, John Wiley and Sons, 2006. 